\title{
OS CONTEÚDOS ATITUDINAIS NO CURRÍCULO DE EDUCAÇÃO FíSICA DO ESTADO DE SÃO PAULO
}

\author{
Amanda Gabriele Milani \\ Universidade Estadual Paulista "Júlio de Mesquita Filho", Rio Claro, São Paulo, Brasil \\ Suraya Cristina Darido \\ Universidade Estadual Paulista "Júlio de Mesquita Filho", Rio Claro, São Paulo, Brasil
}

\begin{abstract}
Resumo
Em 2010, o Estado de São Paulo oficializou o currículo unificado para todos os componentes curriculares. Nesse estudo buscou levantar no currículo e nos cadernos do professor de Educação Física do Estado de São Paulo quais valores, normas e atitudes estão explicitamente apontados. A metodologia utilizada foi de caráter qualitativo, especificamente empregada a análise documental. Foram avaliados o currículo de Educação Física e todos os 16 cadernos do professor do Ensino Fundamental II. Considera-se que esse currículo e os cadernos do professor tratam dos conteúdos atitudinais de maneira pouco aprofundada, sendo necessário dar maior relevância a esses conteúdos no sentido de formar o cidadão crítico e autônomo.
\end{abstract}

Palavras-chave: Educação Física escolar. Valores. Normas. Atitudes. Currículo.

\section{Introdução}

A diversidade cultural nunca foi tão valorizada como está sendo na sociedade contemporânea. Com isso, aprender a lidar e conviver com as diferenças tornou-se uma habilidade fundamental. Em contra partida, nota-se que as relações humanas ainda são marcadas pelo desrespeito e intolerância, gerando um mal-estar ético e moral, que inevitavelmente é refletido na escola (CORTELLA; LA TAILLE, 2005).

Dentre as principais instituições responsáveis pela formação no âmbito moral e ético estão a escola e a família, pois elas colaboram para o desenvolvimento da constituição dos valores do sujeito que irá conviver numa sociedade multicultural com autonomia, respeitando a sua individualidade, sem prejudicar os interesses do coletivo.

A escola é um espaço rico de socialização e proporciona a integração entre todos que compõem a comunidade escolar. Sendo assim, professores, alunos, funcionários, gestores e pais, relacionam-se entre si, cada um com suas atitudes, hábitos, crenças e valores (SARABIA, 1998; ARAÚJO; AQUINO, 2002; DIAS, 2008; D'AUREA- TARDELLI, 2009; TREVISOL, 2009; LA TAILLE, 2010; JUSTO, 2010).

Para La Taille (2010), a questão sobre ser ou não responsabilidade da escola, o ensino de valores já está superada, uma vez que eles se fazem presentes nesse ambiente, mas ainda é preciso discutir "quais" valores devem ser ensinados e como "trabalhá-los" (p. 6). Compartilhando dessa mesma concepção, Aranha (1993) ressalta que a educação será mais coerente e eficaz se for capaz de esclarecer quais são os valores que dão sustentação à Educação.

De acordo com Coll et al. (2000) e Zabala (1998), o ensino de valores pertence à dimensão dos conteúdos atitudinais, que é composta também pelas atitudes e normas. Para os 
autores, tanto os valores, quanto as normas e as atitudes, são conteúdos que devem estar presentes no currículo escolar e serem ensinados na escola por todos os componentes curriculares.

Ainda conforme a perspectiva dos autores, os conteúdos escolares devem ser tratados segundo as dimensões dos conteúdos que abrangem a dimensão conceitual, procedimental e atitudinal. Na área da Educação Física escolar a ampliação da discussão sobre as dimensões dos conteúdos, de acordo com Maldonado et al. (2014), ocorreu, sobretudo, com a publicação dos Parâmetros Curriculares Nacionais - PCNs (BRASIL, 1997).

Ao observar a presença da Educação Física na escola, pode-se verificar uma predominância quase que exclusiva da dimensão procedimental, sendo importante apenas o saber fazer, deixando de lado o saber sobre a cultura corporal e o saber sobre como se deve ser (CASTELLANI FILHO, 1993; DARIDO, 2001; DARIDO; RANGEL, 2005; OLIVEIRA, 1991;).

Apesar da super valorização da dimensão procedimental, sobretudo do ensino dos esportes, a relação da Educação Física na escola com os conteúdos atitudinais não é recente. Ao longo da história, esse componente curricular já esteve associado a diferentes valores, sendo eles: a obediência às regras, rigidez da conduta e do corpo, perfeição da técnica e valorização dos mais habilidosos (MARTINS; FREIRE, 2008). Esses valores estavam embutidos na prática pedagógica do professor que, muitas vezes, confundia-se a um treinador (DARIDO, 2003).

Contudo, esses valores passam a ser contestados a partir da década de 1980, em virtude dos chamados movimentos renovadores que ocorreram na área, cuja finalidade era propor um novo objetivo para Educação Física na escola. Na década de 1990, os PCNs (BRASIL, 1997;1998) sugerem o trato das dimensões dos conteúdos para as aulas de Educação Física, devendo a dimensão atitudinal ser abordada de modo intencional e planejada. Particularmente na Educação Física, Acedo (2009) ressalta que mesmo com quase 20 anos após esses movimentos o trato com valores, normas e atitudes ainda continua no currículo oculto.

Embora muitos autores defendam e apontem a importância da escola tratar dos conteúdos atitudinais, além de documentos oficiais, como a Lei de Diretrizes de Bases da Educação Nacional - LDB (BRASIL, 1996) e os PCNs (BRASIL, 1997; 1998) estabelecerem a formação de atitude e valores como um dos objetivos da instituição escolar, essa formação permanece no currículo oculto, ou seja, na maioria das escolas o tratamento da dimensão atitudinal ocorre de modo inconsciente e incidental (ARAÚJO; AQUINO, 2002; FREIRE et al., 2010; LA TAILLE; DE STEFANO; SHIZU, 2009).

De acordo com Apple (1982), o currículo oculto é entendido como "normas e valores que são implícitas, porém efetivamente transmitidos pelas escolas e que habitualmente não são mencionados na apresentação feita pelos professores dos fins ou objetivos" (APPLE, 1982, p. 127).

Nos últimos dez anos iniciou-se, no Brasil, um movimento de sistematização curricular em diferentes Estados, como por exemplo, no Paraná, Rio de Janeiro, Ceará, Acre, Santa Catarina, Maranhão, Rio Grande do Sul, entre outros. No Estado de São Paulo esse movimento ocorreu a partir de 2008, quando a Secretária da Educação enviou uma proposta de sistematização curricular para todos os componentes curriculares, inclusive Educação Física, para as 5.300 escolas estaduais do Estado de São Paulo. Em 2010, essa proposta passou a ser denominada de Currículo.

No caso da Educação Física, o currículo apresenta uma perspectiva cultural e se ocupa em tratar da cultura de movimento, que são "os aspectos corporais, que se expressam de diversas formas, dentre as quais os jogos, as ginásticas, as danças, as lutas e os esportes" (SÃO PAULO, 2013, p. 224). 
Nesse sentido, cabe à Educação Física partir do conhecimento que os alunos carregam acerca dos elementos da cultura de movimento, oportunizar melhores condições de participação para que esse acervo seja ampliado, aprofundado e compreendido de forma crítica (SÃO PAULO, 2013).

Um conceito fundamental nesse currículo refere-se ao "se-movimentar", considera-se que o aluno ao "se-movimentar" expressa seus desejos, intenções e sentimentos, tornando esse movimento próprio. Por esse motivo o "Se" foi colocado propositalmente antes do verbo, para expressar a ideia de que o sujeito é o autor do seu movimento.

Em relação aos conteúdos propostos, espera-se que no Ensino Fundamental I os alunos vivenciem um grande repertório de movimento, por meio dos jogos, brincadeiras, atividades rítmicas e lutas, pois a partir da segunda etapa do Fundamental haverá maior exigência no que se refere a conceitos e significados presentes nos elementos da cultura de movimento (SÃO PAULO, 2013).

A partir do Ensino Médio, os conteúdos passam a ser trabalhados por meio de uma intersecção com os eixos temáticos, que foi "definido pela dinâmica da cultura de movimento na sociedade atual: corpo, saúde e beleza; contemporaneidade; midias; lazer e trabalho". Essa inter-relação possibilita uma maior discussão sobre os elementos da cultura corporal com os valores presentes na sociedade contemporânea, buscando dar maior significado para a aprendizagem do aluno (VENÂNCO; BETTI, 2011, p.2314).

A Educação Física escolar no currículo não se resume apenas à realização mecânica de movimentos, ou à prática de esporte de modo inconsciente. Nesse documento, ela apresenta uma perspectiva diferenciada, nela o aluno, além de valorizar e desfrutar dos benefícios advindos da cultura de movimento, deve "também perceber e compreender os sentidos e significados das suas diversas manifestações na sociedade contemporânea" (SÃO PAULO, 2013, p.28). Embora esse currículo não adote a perspectiva das dimensões dos conteúdos, é possível reconhecer que há uma preocupação com o aprender a fazer (procedimental), aprender a conhecer (conceitual) e o aprender a ser e se relacionar (atitudinal). De modo geral e, de acordo com o currículo, a Educação deve:

Construir identidade, agir com autonomia e em relação com o outro, bem como incorporar a diversidade, são as bases para a construção de valores de pertencimento e de responsabilidade, essenciais para a inserção cidadã nas dimensões sociais e produtivas. Preparar os indivíduos para o diálogo constante com a produção cultural, num tempo que se caracteriza não pela permanência, mas pela constante mudança - quando o inusitado, o incerto e o urgente constituem a regra -, é mais um desafio contemporâneo para a educação escolar (SÃO PAULO, 2013, p.12).

Ao eleger como finalidade da disciplina na escola a construção da identidade, o agir com autonomia e a valorização da diversidade, o currículo mostra preocupação com uma educação baseada em valores. Seria relevante, dada à abrangência que este documento possui, identificar como está materializada a perspectiva da dimensão atitudinal.

Desse modo, objetiva-se, nesse estudo, levantar no currículo e nos cadernos do professor de Educação Física do Estado de São Paulo quais valores, normas e atitudes estão explicitamente apontados, no que diz respeito particularmente aos conteúdos da Educação Física.

\section{Metodologia}

A metodologia utilizada nesse estudo foi de caráter qualitativo, a técnica de pesquisa empregada foi a análise documental, que apresenta como característica utilizar como fonte de 
coleta de dados documentos que podem ser caracterizados como fontes primárias ou secundárias (MARCONI; LAKATOS, 2011).

A presente pesquisa utilizou o Currículo da área de Linguagens, Códigos e Tecnologias, no qual insere a Educação Física e os cadernos do professor nesse mesmo componente curricular. O Currículo de Educação Física é composto pelo caderno do professor e o caderno do aluno. O professor possui um caderno para cada bimestre, já o aluno possui um caderno a cada dois bimestres, totalizando 28 cadernos anuais e oito vídeos-aulas para os professores, e 14 cadernos anuais dos alunos, para as etapas do Ensino Fundamental II e Ensino Médio.

Essa pesquisa analisou um total de 16 documentos, correspondendo apenas aos cadernos do professor do Ensino Fundamental II e neles foram localizados os aspectos relacionados aos valores, normas e atitudes.

Entendem-se os valores como algo intrinsecamente relacionado ao ser humano e ao meio social. Para Sarabia (1998), os valores são "princípios éticos com respeito aos quais as pessoas sentem um forte compromisso emocional e que empregam para julgar as condutas" (VANDER ZANDEN, 1990 apud SARABIA, 1998, p. 127). Já as normas sociais são definidas como "padrões de conduta compartilhados pelos membros de um grupo social", esses padrões distinguem o que é adequado ou inadequado em diferentes situações. Entendem-se atitudes como predisposições "permanentes" que foram construídas pelo indivíduo por meio de suas experiências anteriores estabelecidas com os diferentes objetos, dada uma mesma situação, o indivíduo tenderá a ter a mesma atitude (SARABIA, 1998).

\section{Resultados e Discussão}

O currículo proposto pelo Estado de São Paulo não adota a perspectiva da dimensão dos conteúdos idealizadas por Coll (2000) e Zabala (1998), porém pode-se perceber claramente a presença das três dimensões na análise do documento.

Os resultados aqui apresentados configuram-se em uma análise do currículo e dos cadernos do professor destinado ao Ensino Fundamental II. Buscou-se verificar quais valores, normas e atitudes estão explicitamente presentes nas aulas de Educação Física propostos pelo currículo do Estado de São Paulo.

Ao analisar o caderno do professor, verificou-se que ele apresenta uma proposta de trabalho com diversificação dos conteúdos indo muito além do "quarteto fantástico" . São propostos o ensino de diferentes elementos da cultura de movimento, como jogos, esportes, lutas, atividades rítmicas e conhecimento sobre o corpo no eixo temático organismo humano, movimento e saúde. Em relação aos conteúdos atitudinais, a análise do currículo permitiu observar a presença de diferentes valores, normas e atitudes.

\section{Valores no currículo do Estado de São Paulo}

O currículo de São Paulo supera alguns paradigmas que marcaram determinados momentos da história da Educação Física na escola, como por exemplo, a divisão da turma por sexo, que era respaldada pelo decreto $n^{0} 69.450 / 71$, e a exclusão dos menos habilidosos (SOARES et. al., 1992). Propõe, também, um trabalho por meio da coeducação, e valoriza a participação de todos os alunos em todos os momentos, avançando em muitas temáticas

\footnotetext{
${ }^{1}$ Expressão usada na área para se referir aos quatro conteúdos esportivos mais ensinados nas aulas de Educação Física, sendo eles o futebol, voleibol, basquetebol e handebol. Na perspectiva tradicional esportivista, esses eram os únicos conteúdos ensinados.
} 
defendidas no interior dos movimentos renovadores (BETTI, 1991; BRACHT, 1999; GONZÁLEZ; SCHWENGBER, 2012).

O Quadro 1 refere-se aos valores que puderam ser observados no currículo, entre eles o valor da cooperação, valorização da cultura local/regional e valorização de outras culturas. A cooperação é o mais presente, sendo mencionado em todos os anos de ensino, nos conteúdos Jogo e Esporte; Esporte (nas modalidades de futsal, ginástica artística, atletismo, basquetebol, voleibol e futebol) e Organização de um festival de dança e campeonato esportivo.

A valorização da cultura local/regional e valorização de outras culturas são os outros valores que puderam ser identificados. Justifica-se a presença desses valores para os alunos conhecerem e apreciarem a diversidade das práticas relacionadas às atividades rítmicas, presentes tanto no âmbito nacional, como internacional. Os resultados podem ser observados no Quadro 1.

Quadro 1. Valores presentes no eixo de conteúdos e nos anos de ensino

\begin{tabular}{|c|c|c|c|c|}
\hline Valores & $6^{\circ}$ ano & $7^{\circ}$ ano & $8^{\circ}$ ano & $9^{\circ}$ ano \\
\hline Cooperação & $\begin{array}{l}\text { Jogo e esporte: } \\
\text { competição } \\
\text { cooperação } \\
\text { Esporte- Futsal } \\
\text { Esporte - } \\
\text { Ginástica Artística } \\
\text { Cooperação }\end{array}$ & $\begin{array}{l}\text { Atletismos - } \\
\text { corridas e saltos } \\
\text { Esporte - } \\
\text { Basquetebol } \\
\text { Esporte- Voleibol }\end{array}$ & $\begin{array}{l}\text { Esporte - } \\
\text { modalidade a } \\
\text { escolher } \\
\text { Esporte- Futebol }\end{array}$ & 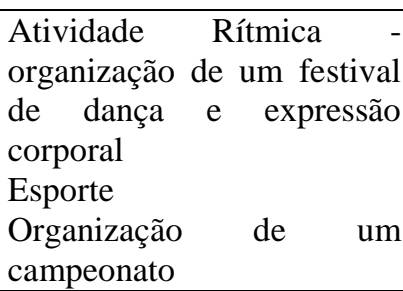 \\
\hline $\begin{array}{l}\text { Valorização } \\
\text { da cultura } \\
\text { local/regional } \\
\text { e valorização } \\
\text { de outras } \\
\text { culturas }\end{array}$ & $\begin{array}{l}\text { Jogo e esporte: } \\
\text { competição } \\
\text { cooperação } \\
\text { (jogos populares) }\end{array}$ & $\begin{array}{l}\text { Atividade Rítmica: } \\
\text { manifestações e } \\
\text { representações da } \\
\text { cultura rítmica } \\
\text { nacional } \\
\text { (cultura regional) }\end{array}$ & $\begin{array}{l}\text { Atividade rítmica- } \\
\text { zouk } \\
\text { (outras culturas) }\end{array}$ & $\begin{array}{l}\text { Esporte }- \text { alternativo } \\
\text { beisebol } \\
\text { (outras culturas) }\end{array}$ \\
\hline
\end{tabular}

Uma possível explicação para cooperação estar presente em todos os anos de ensino, refere-se à intensa crítica realizada na década de 1980 sobre a exacerbação da competitividade e da vitória a qualquer custo, valores presentes no modelo esportivista presentes no ensino das décadas de 1960 e 1970 de grande parte das aulas de Educação Física escolar. Com os movimentos renovadores, buscou-se a superação desse modelo e a cooperação passou a ser cada vez mais valorizada (BETTI, 1991; BROTTO, 1999, BRACHT, 1999; DARIDO, 2003).

Lovisolo, Borges e Muniz (2013) buscaram analisar as propostas dos jogos cooperativos que se sobrepõe aos jogos competitivos, numa perspectiva de educação transformadora baseada em valores sociais humanos. Ao analisar as propostas, os autores reconhecem a importância dos pioneiros dessa temática, dando destaque para Abrahão (2004), Blanco (2007), Brotto (1999), Correia (2006), Orlick (1989), Martini (2005), Monteiro (2006), Soler (2005), considerando importante a expansão dos jogos cooperativos, desde que não os sobreponha à competição, com isso, vale ressaltar que a presença da cooperação não exclui a competição, só lança olhares também possíveis nas aulas sobre a cooperação existente. (LOVISOLO; BORGES; MUNIZ; 2013).

Embora o valor da cooperação esteja presente em todos os anos do Ensino Fundamental, o conteúdo dos jogos cooperativos se restringe apenas ao primeiro bimestre do sexto ano, sendo abordada a diferença entre os jogos cooperativos, competitivos e esporte. Nos outros anos, a cooperação é valorizada para que o aluno compreenda a sua necessidade para o desenvolvimento das práticas esportivas a fim de um melhor aproveitamento destas. 
Com isso, espera-se que os alunos adotem atitudes cooperativas para prática das modalidades esportivas coletivas.

A diversidade é um valor presente no currículo da área de Códigos, Linguagens e suas Tecnologias, sendo importante para o desenvolvimento pessoal do aluno e assegurando-lhe oportunidades de escolhas. De acordo com o currículo:

A educação tem de estar a serviço desse desenvolvimento, que coincide com a construção da identidade, da autonomia e da liberdade. Não há liberdade sem possibilidade de escolhas. Escolhas pressupõem um repertório e um quadro de referências que só podem ser garantidos se houver acesso a um amplo conhecimento, assegurado por uma educação geral, articuladora e que transite entre o local e o global (SÃO PAULO, 2013, p.11).

Com isso, pode-se verificar uma coerência entre o currículo que rege a área de Códigos, Linguagens e suas Tecnologias, com os cadernos do professor de Educação Física. Aprender sobre a diversidade é cada dia mais necessário numa sociedade multicultural, possibilitando uma reflexão sobre a diferença, a fim de romper com atitudes preconceituosas e discriminatórias.

Segundo Moreira e Candau (2003), a discriminação se expressa de diversas formas na escola, vivencia-se uma imersão da cultura da discriminação (grifo do autor), em que o outro é inferior por possuir características indenitárias e comportamentos diferentes.

Por isso a necessidade de se tratar da diversidade na escola, mas os mesmos, autores salientam que não basta apenas incorporar conteúdos e datas comemorativas, mas, sim, "questionar, desnaturalizar e desestabilizar essa realidade constitui um passo fundamental" (MOREIRA; CANDAU, 2003, p. 166), para o avanço no trato da diversidade na escola.

Reconhece-se a diversidade quando se trabalha com a valorização da cultura nacional, que no caso do Brasil é bastante diversificada (TOLEDO et al., 2004). Essa proposta está presente no sexto ano com o conteúdo de jogos e esportes e, no sétimo ano, no conteúdo de atividade rítmica. A valorização de outras culturas aparece no currículo em dois momentos, no oitavo ano com o conteúdo da atividade rítmica, sendo proposto um trabalho com zouk, e no nono ano o beisebol é o conteúdo sugerido como esporte alternativo.

Rangel et al. (2008) considera que o trato da diversidade possibilita uma gama de temas que podem compor os conteúdos, sendo a escolha desses temas, em conjunto com os alunos, uma tarefa importante para o planejamento pautado nas questões culturais. Entretanto, os autores alertam que não basta escolher e ministrar tais conteúdos, é fundamental que se faça a contextualização dos mesmos, estratégia também adotada pelo currículo.

Nota-se, também, uma tentativa de tratar da diversidade dos conteúdos do componente curricular da Educação Física. Nesse quesito, o currículo apresenta-se como um avanço importante para área.

\section{Normas no currículo do Estado de São Paulo}

Segundo Abbagnano (2002), a norma pode ser compreendida por "regra ou critério de juízo", e a regra como "qualquer proposição de natureza prescritiva". Esses conceitos se relacionam e exprimem uma ideia de dever ser, ou seja, recomendam o modo de como se deve agir, com isso as normas e as regras apresentam uma obrigatoriedade no seu cumprimento, em casos de descumprimento sempre há uma sanção ou punição, por exemplo, se um jogador quebra uma regra no esporte ele pode ser punido com cartão ou até mesmo ser expulso, dependendo da gravidade. 
Desse modo, ao considerar as regras dos esportes como conteúdos da dimensão atitudinal referente às normas, específicos da Educação Física, pode-se observar, no quadro 2, que elas estão presentes em todos os anos de ensino.

Quadro 2. Normas presentes currículo de Educação Física do Estado de São Paulo

\begin{tabular}{|c|c|c|c|c|}
\hline Normas & $6^{\circ}$ ano & $7^{\circ}$ ano & $8^{\circ}$ ano & $9^{\circ}$ ano \\
\hline $\begin{array}{ll}\text { Regras } & \text { do } \\
\text { esportes } & \end{array}$ & $\begin{array}{l}\text { - Futsal } \\
\text { - Ginástica } \\
\text { Artística } \\
\text { - Handebol }\end{array}$ & $\begin{array}{l}\text { - Atletismo } \\
\text { - Voleibol } \\
\text { - Ginástica } \\
\text { Rítmica } \\
\text { - Basquete } \\
\text { - Judô }\end{array}$ & $\begin{array}{l}\text { - Atletismo } \\
\text { - Caratê } \\
\text { - Futebol }\end{array}$ & $\begin{array}{l}\text { - Futebol } \\
\text { - Beisebol }\end{array}$ \\
\hline
\end{tabular}

As regras são necessárias para que os jogos e esportes ocorram de forma organizada, justa e igualitária para todos competidores, além de ser uma forma de se entender a lógica do próprio esporte ou jogo em si. Não que na escola as regras devam ser as mesmas do esporte institucional, elas podem e devem ser adaptadas à realidade escolar.

Para Helal (1990, p. 26), as regras nos jogos e esporte apresentam duas finalidades, "organizar a atividade em questão e "complicar" a ação ou objetivo daquela atividade". Com isso, as atividades se tornam mais desafiadoras. Para o autor, isso faz com que "as regras proporcionem graça aos jogos".

Em todas as modalidades esportivas presentes no currículo, sugere-se que o professor ensine as regras, para que os alunos possam entender a lógica dos jogos e esportes, seja para praticá-los, ou apenas para apreciação, usufruindo desses elementos da cultura de movimento no seu dia a dia de forma crítica.

Freire et al. (2010), ao analisarem a presença dos conteúdos atitudinais na prática pedagógica de três professores, também verificaram que dois deles cobram e ensinam as regras dos jogos e esportes para seus alunos. Assim, como nesse estudo, os conteúdos das regras dos esportes também foram classificados como conteúdos relacionados às normas pertencente à dimensão atitudinal.

O currículo, em relação às normas de convivência, não deixa de forma clara como elas devem ser acordadas nas instituições escolares. Em conformidade com Araújo (2002), o modelo de gestão e organização, que rege a maioria das escolas brasileiras, pouco contribui para formar um cidadão democrático, pois espaços autoritários não formam pessoas democráticas. Por isso, seria fundamental que estivesse presente no currículo e nos cadernos do professor de Educação Física orientações para a elaboração das normas escolares pautadas nos princípios e valores democráticos ${ }^{2}$.

No tocante às normas de convivências que também não foram abordadas no currículo, Rodrigues e Darido (2012) apontam a importância de se estabelecer as regras, os combinados e as sanções, quando do descumprimento dessas, em conjunto com os alunos. Mas não só isso é fundamental que se explique por que elas precisam ser acertadas, evidenciando-se seus princípios.

\footnotetext{
${ }^{2}$ Ulisses Ferreira Araújo, em seu livro "A construção de escolas democráticas", aponta sete diferentes aspectos que estão presentes na real democratização dos processos educativos.
} 


\section{As atitudes no currículo do Estado de São Paulo}

São duas as principais atitudes referenciadas no caderno do professor do currículo de São Paulo, autonomia e respeito. A dimensão das atividades referentes à autonomia encontrase nos conteúdos do eixo de conteúdo "Organismo, humano, movimento e saúde" presentes nos três anos do Ensino Fundamental, segundo segmento e está relacionada à autonomia nas práticas regulares de atividade física. Já o tema do respeito, está presente nos conteúdos de diferentes modalidades esportivas, atividades rítmicas e lutas, conforme o Quadro 3.

Quadro 3: Atitudes presentes no currículo de Educação Física do Estado de São Paulo

\begin{tabular}{|c|c|c|}
\hline & \multicolumn{2}{|l|}{ Atitudes } \\
\hline & Autonomia & Respeito \\
\hline $6^{\circ}$ ano & $\begin{array}{l}\text { Organismo humano, movimento e } \\
\text { saúde: capacidades físicas }\end{array}$ & Esporte: Futsal; Handebol. \\
\hline $7^{\circ}$ ano & $\begin{array}{l}\text { Organismo humano, movimento e } \\
\text { saúde: capacidades físicas }\end{array}$ & $\begin{array}{l}\text { Atividade Rítmica: manifestações e } \\
\text { representações da cultura rítmica } \\
\text { nacional. }\end{array}$ \\
\hline $8^{\circ}$ ano & $\begin{array}{l}\text { Organismo humano, movimento e } \\
\text { saúde: capacidades físicas; princípios e } \\
\text { efeitos do treinamento; atividade física } \\
\text { /exercício físico. }\end{array}$ & $\begin{array}{l}\text { Luta: Caratê } \\
\text { Atividade rítmica: zouk } \\
\text { Esporte: Futebol. }\end{array}$ \\
\hline $9^{\circ}$ ano & & $\begin{array}{l}\text { Atividade Rítmica - organização de } \\
\text { um festival de dança e expressão } \\
\text { corporal, e esporte. }\end{array}$ \\
\hline
\end{tabular}

\section{Autonomia}

O currículo de Educação Física buscou com a introdução do tema Organismo humano movimento e saúde, no sexto ano, levar os alunos a compreenderem as relações existentes entre o funcionamento do organismo humano e os conhecimentos necessários para a prática de atividade física, procurando desenvolver uma maior autonomia para os alunos se envolverem com as diferentes possibilidades do "se-movimentar" ao longo de suas vidas (SÃO PAULO, 2013).

A atitude da prática regular da atividade física está presente em todo eixo do conteúdo Organismo, humano, movimento e saúde. O pressuposto é que se os alunos conhecerem os benefícios que a prática regular de exercício oferece nas aulas de Educação Física, eles irão refletir sobre como, onde, quando e de que maneira realizar diferentes práticas, buscando uma vida mais ativa e saudável. Tais pressupostos encontram eco na perspectiva das proposições, por exemplo, de Nahas et al. (1995); Guedes e Guedes (1997; 2002) e Nahas, Silva e Garcia (2012).

No estudo realizado por Freire et al. (2010), uma das professoras analisadas também elege a adoção de um estilo de vida fisicamente ativo como uma atitude que deve ser ensinada em suas aulas, demonstrando a preocupação em desenvolver nos alunos uma consciência da necessidade da prática regular de exercício para uma maior qualidade de vida.

\section{Respeito}

Em uma perspectiva filosófica, Abbagnano (2000) define respeito como o comportamento inspirado no reconhecimento da dignidade própria ou alheia. Os PCNs (BRASIL, 1997) adotam o respeito mútuo como um dos conteúdos do tema transversal ética. 
Esse conteúdo estabelece que as relações de respeito expressam uma reciprocidade, ou seja, o respeito ocorre por todas as pessoas envolvidas de modo igualitário, baseados numa relação horizontal, entre todos os membros da comunidade escolar.

No caderno do professor de Educação de Física do Estado de São Paulo, o respeito aparece em todos os anos de ensino, e ele se refere tanto ao respeito dos limites do seu próprio corpo, quanto ao respeito em relação aos limites corporais e opiniões dos colegas de classe.

Apesar de ser encontrada a temática no documento de Educação Física, entende-se que o respeito não é uma atitude tratada apenas nas aulas de Educação Física, ele é fundamental para o convívio social, devendo ser abordado por todos os componentes curriculares por meio da transversalidade, possibilitando um melhor convívio escolar, sendo os conflitos resolvidos por meio dele e do diálogo (BRASIL, 1997).

\section{Considerações Finais}

Com a elaboração do currículo unificado no Estado de São Paulo, a sistematização dos conteúdos passou a ser uma realidade para a Educação Física escolar. Esse fato foi alvo de bastante polêmica e gerou grande repercussão na área acadêmica. Nesse estudo, buscou-se identificar no currículo e nos cadernos do professor quais valores, normas e atitudes estão explicitamente presentes.

Vale ressaltar que as pesquisas educacionais voltadas para educação na perspectiva da formação em valores e atitudes teve um aumento nos últimos anos (LA TAILLE, 2002). Ainda, porém, há poucos trabalhos com essa temática, especificamente na área da Educação Física (ACEDO, 2009; TAVARES, 2012).

O Currículo de Educação Física do Estado de São Paulo em relação aos conteúdos atitudinais objetiva desenvolver atitudes de autonomia dos alunos em relação às práticas regulares de atividade física, assim como o respeito aos seus próprios limites corporais e às pessoas com as quais convivem.

A cooperação e a valorização de diferentes culturas/diversidade são os valores que mais aparecem na análise do currículo presentes do sexto ao nono ano, nos conteúdos de jogo e esporte, esporte e atividade rítmica. Esses valores têm como finalidade formar indivíduos cooperativos para atuar na sociedade e que saibam conviver e valorizar a diversidade. As normas se restringiram às regras presentes nas modalidades esportivas, deixando de lado outras orientações que podem ser relevantes na prática pedagógica, como estabelecimento de princípios e regras para a condução das aulas.

A análise dos resultados permitiu verificar que no Currículo da Educação Física do Estado de São Paulo os valores, normas e atitudes são propostos e estão relacionados à formação do cidadão. Os cadernos do professor não abarcam um conjunto amplo de valores, normas e atitudes. Na verdade, parece haver ainda ênfase nas dimensões procedimentais e conceituais.

Considera-se a importância da formação inicial em oportunizar discussões voltadas para o tema de valores, orientando os professores no trabalho com dimensão atitudinal e os aproximando dessa temática. Ressalta-se ainda a complexidade do assunto. Por isso, sugeremse mais pesquisas nessa temática a fim de reunir maiores contribuições para a Educação, Educação Física e para a sociedade. 


\title{
ATTITUDINAL CONTENTS IN THE CURRICULUM OF PHYSICAL EDUCATION OF THE SATE OF SÃO PAULO
}

\begin{abstract}
In 2010 the State of São Paulo formalized the unified curriculum to all curriculum components. In this study we attempted to identify in the curriculum and in the notebooks of the Physical Education teachers of the State of São Paulo which values, norms and attitudes are explicitly pointed out. The methodology used was qualitative, specifically used the document analysis. We evaluated the curriculum of Physical Education and all 16 notebooks of the Secondary School teacher. It is considered that this curriculum and teacher's notebooks deal with attitudinal contents in a superficial way, therefore, it is necessary to give greater importance to these contents in order to form a critical and autonomous citizen.
\end{abstract}

Keywords: Physical Education. Standard values. Attitudes. Curriculum.

\section{LOS CONTENIDOS ACTITUDINALES EN EL CURRÍCULO DE EDUCACIÓN FÍSICA DEL ESTADO DE SÃO PAULO}

\section{Resumen}

En 2010, el Estado de São Paulo oficializó el currículo unificado para todos los componentes curriculares. En este estudio busco analizar, en el currículo y en los cuadernos de los maestros de Educación Física del Estado de São Paulo, los valores, las normas y las actitudes marcados explícitamente. La metodología utilizada en este artículo fue de carácter cualitativa, empleando específicamente el análisis documental. Se evaluaron el currículo de Educación Física y los 16 cuadernos del maestro de la segunda parte de la Enseñanza Fundamental. Se considera que ese currículo y los cuadernos de los maestros que se ocupan de los contenidos actitudinales de manera superficial, siendo necesario dar mayor importancia a esos contenidos con el fin de formar ciudadanos críticos y autónomos.

Palabras clave: Educación Física escolar.Valores. Normas. Actitudes. Currículo.

\section{Referências}

ABBAGNANO, N. Dicionário de Filosofia. 4. ed. São Paulo: Martins Fontes, 2002.

ABRAHÃO, S. R. A relevância dos jogos cooperativos na formação dos professores de educação física: uma possibilidade de mudança paradigmática. 2004. 117f. Dissertação (Mestrado em Educação) - Universidade Federal do Paraná, Curitiba, 2004. Disponível em: <http://dspace.c3sl.ufpr.br:8080/dspace/bitstream/handle/1884/27945/R\%20-\%20D\%20\%20SERGIO\%20ROBERTO\%20ABRAHAO.pdf?sequence=1>. Acesso em: 07 dez. 2014.

ACEDO, L. M. Valores e atitudes na prática pedagógica do professor de educação física. 2009. 114f. Dissertação (Ciência da Motricidade) - Instituto de Biociências, Universidade Estadual Paulista "Júlio de Mesquita Filho", Rio Claro, 2009.

ARAUJO, U. F. A construção de escolas democráticas. São Paulo: Editora Moderna, 2002. V. 1. 160p.

APPLE, M. Ideologia e Currículo. São Paulo: Brasiliense, 1982.

ARANHA, M. L. A. Filosofia da Educação. São Paulo: Ed. Moderna, 2006. 
ARAUJO, U. F.; AQUINO, J. G. Os direitos humanos na sala de aula: a ética como tema transversal. 3. ed. São Paulo: Editora Moderna, 2002. v. 1. 144p.

BETTI, M. Educação Física e sociedade. São Paulo: Movimento, 1991.

BLANCO, M. R. Jogos cooperativos e educação infantil: limites e possibilidades. 181f. Dissertação (Mestrado em Educação) - Universidade de São Paulo, São Paulo, 2007.

BRACHT, V. A constituição das teorias pedagógicas da educação física. Cadernos do CEDES (UNICAMP), Campinas, v. 19, n. 48, 1999, p. 69-88. Disponível em: <http://www.scielo.br/pdf/ccedes/v19n48/v1948a05.pdf>. Acesso em: 07 dez. 2014.

BRASIL. Ministério da Educação e do Desporto. Lei de Diretrizes e Bases da Educação Nacional. Brasília: $\quad$ MEC, $1996 . \quad$ Disponível em: <http://www.planalto.gov.br/ccivil_03/LEIS/19394.htm>. Acesso em: 07 dez. 2014.

BRASIL. Parâmetros curriculares nacionais: educação física/ Secretaria de Educação Fundamental. Brasília: Mec/ SEF, 1997.

BRASIL. Parâmetros curriculares nacionais: educação física/ Secretaria de Educação Fundamental. Brasília: Mec/ SEF, 1998.

BROTTO, F. O. Jogos cooperativos: se o importante é competir, o fundamental é cooperar. Santos (SP): Projeto Cooperação, 1999.

CASTEllani FILHO, L. Pelos meandros da Educação Física. Revista Brasileira de Ciências do Esporte, v. 14, n. 3, p. 119-125, 1993.

COLL, C. et al. Os conteúdos na reforma. Porto Alegre: Artmed, 2000.

CORREIA, M. M. Trabalhando com jogos cooperativos: em busca de novos paradigmas na Educação Física. Campinas: Papirus, 2006.

CORTELLA, M. S.; LA TAILLE, Y. Nos labirintos de moral. Campinas, SP: Papirus 2005.

DARIDO, S. C. Os conteúdos da Educação Física escolar: influências, tendências, dificuldades e possibilidades. Perspectivas da educação física escolar, Niterói, v. 2, n.1, p. $5-25,2001$,

DARIDO, S. C. Educação física na escola: questões e reflexões. Rio de Janeiro: Guanabara Koogan, 2003.

DARIDO, S. C. (Org.); RANGEL, I. C. A. (Org.). Educação física na escola: implicações para a prática pedagógica. 3. ed. Rio de Janeiro: Guanabara Koogan, 2005. v. 1.293 p.

D'AUREA-TARDELI, D. Adolescência, personalidade e projeto de vida solidário. In: LA TAILLE, Y. D.; DE STEFANO, M. S. M.; SHIZU, A. M. [et al.] Crise de valores ou valores em crise. Porto Alegre: Artmed, 2009. 
DIAS, A. A. A escola como espaço de socialização da cultura em direitos humanos. In: ZENAIDE, Maria de Nazaré Tavares; SILVEIRA, Rosa Maria Godoy; DIAS, Adelaide Alves. (Org.). Direitos Humanos: capacitação de educadores - Fundamentos culturais e educacionais da Educação em Direitos Humanos - Vol. 2. 1. ed. João Pessoa: Editora Universitária da UFPB, 2008, v. 2, p. 155-160. Disponível em: <http://www.dhnet.org.br/dados/cursos/edh/redh/04/4_3_adelaide.pdf >. Acesso em: 07 dez. 2014.

FREIRE, E. S.; VERENGUER, R. C. G.; SORIANO, J. B.; SANTOS, E. A.; ALMEIDA PINTO, M. R. A dimensão atitudinal nas aulas de Educação Física: conteúdos selecionados pelos professores. Revista da Educação Física/UEM, v. 21, p. 223-235, 2010. Disponível em: <http://periodicos.uem.br/ojs/index.php/RevEducFis/article/view/7643/6053>. Acesso em: 07 dez. 2014.

GONZÁLEZ, F.J.; SCHWENGBER, M.S.V. Práticas pedagógicas em educação física: espaço, tempo e corporeidade. Erechim: Eldebra, 2012.

GUEDES, D. P.; GUEDES, J. E. R. P. Crescimento, composição corporal e desempenho motor em crianças e adolescentes. São Paulo: CLR Balieiro, 1997. 362p.

GUEDES, D. P.; GUEDES, J. E. R. P. Crescimento, composição corporal e desempenho motor de crianças e adolescentes. 2. ed. São Paulo: CLR Balieiro, 2002. 362 p.

HELAL, Ronaldo George. O que é sociologia do esporte? São Paulo: Brasiliense, 1990.

JUSTO, J. S. Escola no epicentro da crise social. In: LA TAILLE, Y. D.; Indisciplina/disciplina: ética, moral e ação do professor. 3. ed. Porto Alegre: Mediação, 2010.

LA TAILLE, Y. De. Vergonha, a ferida moral. 2. ed. Petrópolis: Vozes, 2002. 287 p.

LA TAILlE, Y. D.; DE STEFANO, M. S. M.; SHIZU, A. M. Crise de valores ou valores em crise. 1. ed. Porto Alegre: Artmed, 2009. v. 1. 198 p.

LA TAILLE, Y. D. A escola e os valores: a ação do professor. In: Indisciplina/disciplina: ética, moral e ação do professor. 3. ed. Porto Alegre: Mediação, 2010.

LOVISOLO, H. R.; BORGES, C. N. F.; MUNIZ, I. B. Competição e cooperação: na procura do equilíbrio. Revista Brasileira de Ciências do Esporte, v. 35, p. 1, 2013. Disponível em: <http://www.scielo.br/pdf/rbce/v35n1/a11v35n1.pdf>. Acesso em: 07 dez. 2014.

MALDONADO, D. T.; BOCCHINI, D. BARRETO, A.; RODRIGUES, G. M.; As dimensões atitudinais e conceituais na educação física escolar. Pensar a Prática. Goiânia, v. 17, n. 2, p. 546-559, jan./mar. 2014. Disponível em: <http://www.revistas.ufg.br/index.php/fef/article/view/23825/16758>. Acesso em: 07 dez. 2014. 
MARCONI, M. A.; LAKATOS, E. M. Técnicas de pesquisa: planejamento e execução de pesquisas, amostragens e técnicas de pesquisas, elaboração, análise e interpretação de dados. 7. ed. - São Paulo: Atlas, 2011.

MARTINI, R. G. A relevância dos jogos cooperativos na formação dos professores de educação física: uma possibilidade de mudança paradigmática. 2005. 143 f. Dissertação (Mestrado em Psicologia da Educação)- Pontifícia Universidade Católica de São Paulo, São Paulo, 2005. Disponível em: <http://www.sapientia.pucsp.br/tde_busca/arquivo.php?codArquivo=1274>. Acesso em: 07 dez. 2014.

MARTINS, C. D.; FREIRE, E. S. Conteúdos Atitudinais nas aulas de Educação Física: um estudo de caso. Revista Mackenzie de Educação Física e Esporte, v. 7, p. 21-28, 2008. Disponível em: <http://editorarevistas.mackenzie.br/index.php/remef/article/viewFile/1485/1132>.Acesso em: 07 dez. 2014.

MONTEIRO, F. Transformação das aulas de educação física: uma intervenção através dos jogos cooperativos. 222 f. Dissertação (Mestrado em Educação Física) - Faculdade de Educação Física, Universidade Estadual de Campinas, Campinas, 2006.

MOREIRA, A. F. B.; CANDAU, V. Educação escolar e cultura(s): construindo caminhos. Revista Brasileira de Educação (Impresso), São Paulo, v. 23, p. 156-168, 2003. Disponível em: < http://www.scielo.br/pdf/rbedu/n23/n23a11>. Acesso em: 07 dez. 2014.

NAHAS, M. V.; PIRES, M. C.; WALTRICK, A. C. A.; BEM, M. F. L. Educação para atividade fisica e saúde: implementação de proposta curricular experimental. Revista brasileira de atividade física e saúde, Londrina, PR, v. 1, n.1, p. 57-65, 1995. Disponível em: <http://periodicos.ufpel.edu.br/ojs2/index.php/RBAFS/article/viewFile/452/496>. Acesso em: 07 dez. 2014.

NAHAS, M. V.; SILVA, K. S.; GARCIA, L.M.T. Atividade física na infância e adolescência. In: CARVALHO, J. A. M.; MAREGA, M. (Org.). Manual de atividades físicas para prevenção de doenças. Rio de Janeiro: Elsevier, 2012, v. 1, p. 145-161.

OLIVEIR, M. J.G. M. Educação Física escolar: construindo castelos de areia. Revista Paulista de Educação Física, v. 5, n .1/2, p.5-11, 1991.

ORLICK, T. Vencendo a competição. São Paulo: Círculo do Livro, 1989.

RANGEL, I. C. A.; SILVA, E. V. M.; SANCHES NETO, L.; DARIDO, S. C.; IÓRIO, L. S.; MATHIESEN, S. Q.; GALVÃO, Z. ; RODRIGUES, L. H.; LORENZETTO, L. A.; CARREIRO, E. A.; VENÂNCIO, L . Educação Física Escolar e multiculturalismo: possibilidades pedagógicas. Motriz (Rio Claro), v. 14, p. 156-167, 2008. Disponível em:<http://www.ufgd.edu.br/reitoria/neab/downloads/educacao-fisica-escolar-e-

multiculturalismo-possibilidades-pedagogicas-2013-varios-autores $>$. Acesso em: 07 dez. 2014.

RODRIGUES, H. A.; DARIDO, S. C. Basquetebol na escola: uma proposta didáticopedagógica. Rio de Janeiro: Guanabara Koogan, 2012. v. 1. 132p . 
SÃO PAUlO (Estado). Secretaria da Educação. Proposta curricular do Estado de São Paulo: Educação Física / Coord. Maria Inês Fini. São Paulo: SEE, 2013.

SARABIA, B. A aprendizagem e o Ensino das Atitudes. In: COLL, C.; POZO, J. I.; SARABIA, B.; VALLS, E. (Org.). Os conteúdos na reforma: ensino e aprendizagem de conceitos, procedimentos e atitudes. Trad. Beatriz Afonso Neves. Porto Alegre: Artmed, 1998.

SOARES, C. L.; TAFFAREL, C. N. Z.; VARJAL, E.; FILHO, L. C.; ESCOBAR, M. O.; BRACHT, V.Metodologia do Ensino de Educação Física. São Paulo: Cortez, 1992.

SOARES, C. L. Educação Física: Raízes européias e Brasil. 4. ed. Campinas, 2007. v. 1. p. 167.

SOLER, R. Jogos cooperativos. Rio de Janeiro: Sprint, 2005.

TOLEDO, E.; BELLINI, J. M.; AMINE, R. RODRIGUES, R. V. A relevância do folclore como conteúdo da Educação Física escolar. Revista Corpoconsciência, Santo André, n. 14, p. 55-77, jul./dez. 2004.

TREVISOL, M. T. C.; Tecendo os sentidos atribuídos por professores e ensino fundamental ao médio profissionalizante sobre a construção de valores na escola. In: LA TAILLE, Y. D.; DE STEFANO, M. S. M.; SHIZU, A. M. [et al.] Crise de valores ou valores em crise. Porto Alegre: Artmed. 2009.

VENÂNCIO, L; BETTI, M. A PROPOSTA CURRICULAR DE EDUCAÇÃO FÍSICA DO ESTADO DE SÃO PAULO (BRASIL): REFLEXÕES E PROBLEMATIŻAÇÕES SOBRE UM PROCESSO EM ANDAMENTO. In: V Colóquio Luso Brasileiro sobre questões curriculares, 2010, Cidade do Porto/Portugal. V Colóquio Luso Brasileiro sobre questões curriculares, 2010. p. 2523-2535.

ZABALA, A. A prática educativa: Como ensinar. Porto Alegre: ARTMED, 1998.

Recebido em: 09/12/2014

Revisado em: 16/07/2015

Aprovado em: 02/12/2015

Endereço para correspondência:

manditasgm@hotmail.com

Amanda Gabriele Milani

Universidade Estadual Paulista "Júlio de Mesquita Filho"

Av. 24 A, No 1515

Bela Vista

13506-000 - Rio Claro, SP - Brasil 